\title{
Dietary calcium intake in a cohort of elderly patients already in drug therapy for osteoporosis. Is it possible and how to modify the eating habits before calcium supplementation?
}

\author{
Ciro Manzo, ${ }^{1}$ Maria Teresa Russo ${ }^{2}$ \\ ${ }^{1}$ Rheumatological Outpatient Clinic; and ${ }^{2}$ Orthopedic Outpatient Clinic, Mariano Lauro Hospital, Sant'Agnello (NA), Italy
}

\begin{abstract}
Inadequate intake of calcium via the diet is very common in patients taking drugs for osteoporosis. We have evaluated 302 consecutive elderly patients (68.6 median age) attending our Rheumatological and Orthopedic Outpatient Clinics using a questionnaire for evaluation of dietary calcium intake. Two hundred and forty of these had a questionnaire score $<7$ (indicative of a poor intake of calcium, less than $1000 \mathrm{mg}$ /day) and 193/240 were not taking any calcium supplements. A discussion with the patient about the individual questions in the questionnaire allowed to change some taboo and to get a questionnaire score $>7$ in 205/240 after an average period of 3-6 months. In the 35 patients in which this was not possible, the exact knowledge of calcium dietary intake (poor or absent) has allowed a tailored calcium supplementation.
\end{abstract}

\section{Introduction}

Inadequate intake of calcium via the diet is common among Caucasians, and this is even more relevant in elderly population. ${ }^{1}$ In all randomized clinical trials on the effect of drugs with fracture prevention as primary endpoint, ${ }^{2,3}$ an adequate dosage of calcium daily $(1000 \mathrm{mg} / \mathrm{die}$ as average) was required (as well as an adequate supplementation with vitamin $\mathrm{D}$ ) both in the intervention group and in the placebo group. Nevertheless, frequently the determination of dietary calcium is not part of the evaluation of patient with osteoporosis and so in the clinical practice the drugs for osteoporosis are frequently prescribed without

Correspondence: Ciro Manzo, Rheumatological Outpatient Clinic, Mariano Lauro Hospital, viale dei Pini 1, 80065 Sant'Agnello (NA), Italy.

Tel.: +39.081.8724320; +39.338.9436790.

E-mail: cirmanzo@libero.it

Key words: Calcium intake; osteoporosis, diet.

Conflict of interest: the authors declare no potential conflict of interest.

Received for publication: 16 January 2015.

Accepted for publication: 16 February 2016.

This work is licensed under a Creative Commons Attribution NonCommercial 4.0 License (CC BY-NC 4.0).

CCopyright C. Manzo and M.T. Russo, 2016

Licensee PAGEPress, Italy

Italian Journal of Medicine 2016; 10:42-44

doi:10.4081/itjm.2015.582 making sure that the patient has an adequate calcium intake.

\section{Materials and Methods}

In the period from November 2012 to March 2013 we assessed by a questionnaire the intake of calcium via the diet in 302 elderly patients consecutively referring to Rheumatological and Orthopedic Outpatient Clinics of Mariano Lauro Hospital in Sant'Agnello (province of Naples), already in drug therapy for osteoporosis. The questionnaire we used (Table 1) has been validated in an Italian population. ${ }^{4}$ It is a questionnaire easy to use and fast. A score below 7 was indicative of inadequate calcium intake $(<1000 \mathrm{mg} /$ die $)$ via the diet. The average age was 68.6 years (min 60

Table 1. Questionnaire for evaluation of dietary calcium intake.

\begin{tabular}{lc}
\hline Milk (skimmed or full-cream) & \\
\hline One coffee cup & 1 point \\
One glass & 2 points \\
Half liter & 5 points \\
Yoghurt & 2 points \\
Cheese (50 g at least) & \\
Ricotta, mascarpone & 1 point \\
Parmesan, taleggio, fontina, etc. & 4 points \\
Grana, pecorino, Emmenthal & 4 points \\
Sea-fishes (100 g) & 1 point \\
Vegetables (100 g at least) & \\
Broccoli, turntip greens, beans, chickpeas, etc. & 1 point \\
\hline Mineral or tap water (1 L at least) & 2 points \\
\hline
\end{tabular}


- max 83); 281 were female. Contrary to others studies in which the questionnaires for evaluation of dietary calcium intake were self-administered, we decided to proceed with the administration of the questionnaire in the form of questions in order to confront the patient on every item of the questionnaire and evaluate with him whether the eating habits could be somehow modified. The questions were about the eating habits both in general and in relation to the previous week. When and where possible, we provided practical tips for increasing the amount of calcium intake via the diet. After 3-6 months on average, in these 302 patients we re-administered the same questionnaire. Over the next year, 288 of them came back to visit. All had retained the dietary advice that we have initially given.

\section{Results}

Only 62 patients (equal to $20.5 \%$ of the total) achieved a score questionnaire above 7 . Of the remaining 240 (79.5 percentage), 193 were not taking any calcium supplements; 159 received supplementation with vitamin D only (mostly 25,000 UI cholecalciferol per $o s$, weekly) (Table 2). As reported in Figure 1, 67\% of our patients received no milk via the diet. The presence of high serum cholesterol has been the most frequent cause of limiting calcium intake with food (milk in the first place, but also cheese and yogurt). The second limiting factor was represented by a stated/alleged milk intolerance (especially milk sugars). Besides, mineral waters with low amount of calcium were preferred because the taste was more pleasant and considered lighter. Very few were used to drink tap water (Figure 2). The discussion concerning the single items of questionnaire pointed out some considerations: i) many of them did not know that the skim milk contains, for the same volume, even more calcium than the fullcream milk; ii) the majority of those who had declared a lactose intolerance was not aware of the fact that aged cheese (parmesan, gorgonzola, pecorino, taleggio, etc.) have not lactose; iii) many patients did not know that tap water has an adequate amount of calcium. We suggested them to drink skim milk (at least a glass), to eat little portions $(60-80 \mathrm{~g})$ of aged cheese ( 2 or 3 times a

Table 2. Clinical features of enrolled patients.

\begin{tabular}{lc}
\hline Gender (female/male) & $281 / 21$ \\
\hline Age (years), mean & $68.6(\min 60, \max 83)$ \\
\hline Questionnaire score $>7$ & $62(20.5 \%)$ \\
\hline Questionnaire score $<7$ & $240(79.5 \%)$ \\
\hline Calcium supplementation & $47 / 240$ \\
\hline Vitamin D supplementation & $159 / 240$ \\
\hline
\end{tabular}

week), and to drink at least a liter and a half of tap water or water with adequate calcium. After a period of 3-6 months, we have re-evaluated the same cohort of 302 patients with the same questionnaire: the patients with a questionnaire score $>7$ were 205 to the initial 62 ; only 35 maintained a score $<7$. Only in these 35 patients, we have made a calcium supplementation recommending $500 \mathrm{mg}$ /day if dietary calcium was poor and $1000 \mathrm{mg}$ if this was almost absent.

\section{Discussion and Conclusions}

Although there is a considerable scientific evidence about the usefulness and effectiveness of calcium on bone metabolism, its routine assessment continues to be modest, even in patients already on drug therapy for osteoporosis. On the other hand, the possibility that excessive intake of calcium can lead to an increased risk of myocardial infarction and/or ischemic brain lesions has been repeatedly highlighted in the literature..$^{5-7}$ The absorption of calcium is more regular when we use calcium via the diet regard to calcium via the supplemen-

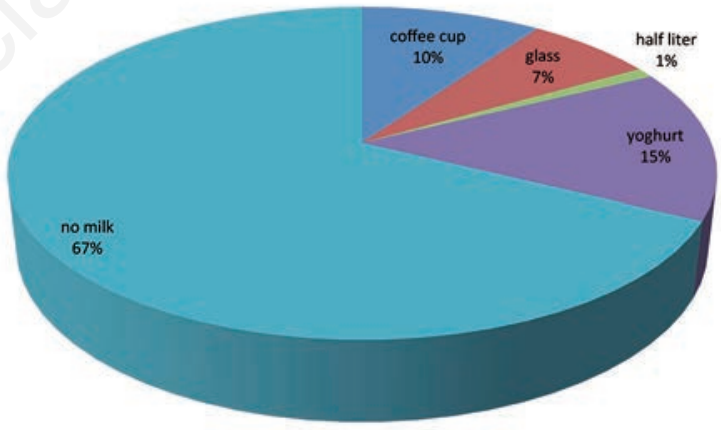

Figure 1. Daily intake of milk, as a percentage.

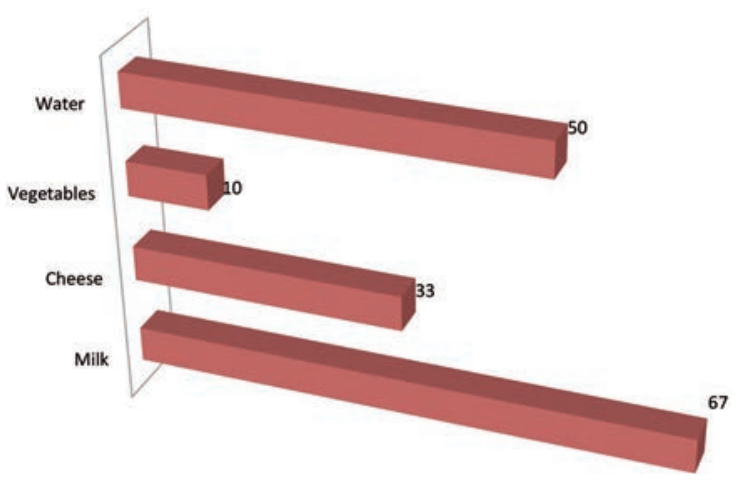

Figure 2. Percentages of elderly patients with an inadequate score for calcium intake: assessment for groups of nutrients. 
tation. ${ }^{8}$ Calcium intake via the diet reduces considerably the possibility of a transient rise in serum calcium levels that many authors consider the main cause of the increased risk of vascular calcifications. All these considerations propose the importance for a calcium supplementation tailored to each elderly patient. ${ }^{9}$ The interactive discussion with each of the elderly patients enrolled in our study about every specific items of the questionnaire allowed to verify the weight of some taboo in influencing food choices and eating habits, the removal of which - where possible - has resulted in significant improvement of score questionnaire. Moreover, even in the very few patients in whom this was not possible, the exact knowledge of dietary calcium intake has allowed a tailored calcium supplementation.

\section{References}

1. Moyer V, on behalf of the U.S. Preventive Services Task Force. Vitamin D and calcium supplementation for prevent fractures in adults: U.S. Preventive Services Task Force Recommendation Statement. Ann Intern Med 2013;158:691-6.

2. Sambrook P, Cooper C. Osteoporosis. Lancet 2006;367: 2010-8
3. Cummings BR, San Martin J, McClung MR, et al. Denosumab for prevention of fractures in postmenopausal women with osteoporosis. N Engl J Med 2009;361:756-65.

4. Rossini M, Maddali Bongi B, La Montagna G, et al. Vitamin D deficiency in rheumatoid arthritis: prevalence, determinants and associations with disease activity and disability. Arthritis Res Ther 2010;12:R216.

5. Bolland MJ, Barber PA, Doughty RN, et al. Vascular events in healthy older women receiving calcium supplementation: randomized controlled trial. BMJ 2008; 336:262-8.

6. Lewis JR, Calver J, Zhu K, et al. Calcium supplementation and the risks of atherosclerotic vascular diseases in older women: results of a 5-year RCT and a 4,5-year follow up. J Bone Miner Res 2011;26:35-41.

7. Payne ME, McQuoid DR, Steffens DC, Anderson JJ. Elevated brain lesions volumes in older adults who use calcium supplements: a cross-sectional clinical observational study. Br J Nutr 2014;112:220-7.

8. van der Velde RY, Brouwers JRBJ, Geusens PP, et al. Calcium and vitamin D supplementation: state of the art for daily practice. Food Nutr Res 2014;58:21796.

9. Michaelsson K, Melhus H, Warensjo E, et al. Long term calcium intake and rates of all cause and cardiovascular mortality: community based prospective longitudinal cohort study. Br J Med 2013;346:1228. 